\title{
Perception of Fathers Rejection in Adolescents
}

\author{
Dr. Sanjeev $\operatorname{Kumar}^{1 *}$
}

\section{ABSTRACT}

The emotional immaturity of parents generates feeling of rejection. Another factor that adversely affects the perception of fathers rejection in adolescents, is marital adjustment of parents. The present study was undertaken to find out the effects and interaction among emotional maturity, marital adjustment of parents and sex of adolescents on the perception of fathers rejection in adolescents. Emotional maturity and marital adjustment of parents are evaluated through Emotional Maturity Scale developed by Dr. Y. Singh \& Dr. M. Bhargava and Comprehensive marital Adjustment Inventory developed by Prof. O. P. Mishra respectively. Parents-Child relationship Scale developed by Dr. Nalini Rao was used to measure rejecting experience of adolescents. 2x2x2 ANOVA was used to compute results. Results shows that emotional maturity and marital adjustment of the parents and Sex of adolescents strongly influence the rejecting perception of adolescents.

\section{Keywords: Perception, Adolescents, Emotional Maturity}

Emotional maturity of parents is a effective determinant to shaping the personality, attitude, behavior and adjustment of the adolescents in to accepting responsibility, making decision, teaming with groups, developing healthy relationships and enhancing self worth, The emotional immaturity of parents generates feeling of rejection. Another factor that adversely affects the perception of father's rejection in adolescents is marital adjustment of parents.

The parents, who are emotionally mature, martially adjusted and are mature enough to handle various emotional states without disturbing their relationship with their adolescents follow authoritative style of parenting. Parents with high emotional maturity and high marital adjustment are better able to handle problems of their adolescents and hence have better relationship with their adolescents. Parents, who use low level of assertion, high level of warmth and inductive discipline and who encourage participation in family decision making, have morally mature adolescents. (Boyes and Allen, 1993)

\footnotetext{
${ }^{1}$ Asst. Professor, Department of Psychology, Nehru P.G. College, Lalitpur, U.P., India *Responding Author

(C) 2016, S Kumar; licensee IJIP. This is an Open Access Research distributed under the terms of the Creative Commons Attribution License (http://creativecommons.org/licenses/by/2.0), which permits unrestricted use, distribution, and reproduction in any Medium, provided the original work is properly cited.
} 


\section{Perception of Fathers Rejection in Adolescents}

The adolescents form homes which were friendly, cheerful and orderly appeared to have matured in to parents who in turn were able to accept their adolescents. Those from homes where the parents were emotionally immature, martially maladjusted, irritable, quarrelsome and inconsistent tended to mature in to adults who later rejected their own adolescents. Rejected adolescents tended to be less friendly, to be more rebellious, to face the future less confidently and to indulge in more self-pity then accepted children. The feeling of rejection by parents makes children become hesitant, aggressive and hostile in relation to others. The father's lack of emotional support and acceptance in childhood appears to be related with emotional and behavioral problems and maladjustment in adult's Life (Rohner, 1998).

Marks (2006) Found that high level of a adolescent's well being was related to higher levels of father- adolescents relationship quality and parental warmth. Kuterovac-Jogodic and Kerests (1997) found that total aggression score of young adults was predicted by their father's undifferentiated rejection, where as their extroversion was associated father's warmth and affection. Poor psychological adjustment was observed among children who perceived their parents as rejecting because physical punishment and corporal punishment resulted in psychological maladjustment (Rohner, Bourque \& Elordi, 1996).

The child who is loved \& protected is likely as we have said, to be better able to face the demands of life outside the home than child who has been rejected and neglected. Ronald Rohner (1986) proposes Parental Acceptance and Rejection theory. In PAR Theory, parental rejection is conceptualized as the absence or withdrawal of parental affection, care and love to which we add the presence of some behaviors and feeling that hurt the child on both physical and psychological levels, (Rohner, Khaleque and Cournoyer, 2005). The researches carried out on several cultures for almost half a century show that parental rejection may be lived as a combination of four main forms of expression (1) distance and lack of affection as opposed to affection and warmth. (2) Aggressiveness and hostility (3) indifference and neglect. (4) Undifferentiated rejection (Rohner, 2004). This undifferentiated rejection refers to individual's beliefs that their parents do not really care about them or love them sincerely, though there may not be clear behavioral indicators for neglect, lack of affection or parental aggressiveness towards them (Rohner, 2004). The opposite of parental rejection is parental acceptance signifying affection, warmth, care, comfort, attention, support or merely love that children receive from their parents. Parental rejection and acceptance from together, the parental affection representing the quality of affective live between children and their parents (Rohner 1986; Rohner et. al., 2005).

A great part of parental rejection is symbolic (Kagan, 1978). Parental acceptance and rejection as perceived by teenagers have consistent effects on the psychological adaptation of children and teenagers (Rohner, 1991). The Perception of parental rejection especially tend to be accompanied by a weak psychological adaptation which includes (a) anger, hostility, aggression (b) negative self-esteem (c) negative self-adequacy (d) emotional instability (e) emotional unresponsiveness 


\section{Perception of Fathers Rejection in Adolescents}

(f) negative worldview (g) dependence or defensive independence depending on the form, frequency, timing and intensity of perceived rejection (Rohner et. al.,2005).

The painful experience of being rejected by parents appears in terms of physical neglect, denial of affection, lack of interest, lack of respect, cruelty and abusive treatment ,(Symands,1939). Feeling of rejection in the child promotes insecurity, inferiority, inadequacy, isolation and anxiety (Dhar, U., 1983).

The present study was undertaken to find out the effect and interaction among emotional maturity and marital adjustment of parents and sex of adolescents on perception of fathers rejection in adolescents.

\section{METHOD}

Design

The details of the elements in the paradigm are given in table-1

Table 1. Distribution of Respondents

\begin{tabular}{|c|c|c|c|c|}
\hline \multirow{2}{*}{$\begin{array}{c}\text { Parent's marital } \\
\text { adjustment }\end{array}$} & \multicolumn{4}{|c|}{ Parent's Emotional Maturity } \\
\cline { 2 - 5 } & \multicolumn{3}{|c|}{ High } & Low \\
\cline { 2 - 5 } & Boys & Girls & Boys & Girls \\
\hline High & $\mathrm{N}=20$ & $\mathrm{~N}=20$ & $\mathrm{~N}=20$ & $\mathrm{~N}=20$ \\
\hline Low & $\mathrm{N}=20$ & $\mathrm{~N}=20$ & \multicolumn{2}{c}{} \\
\hline
\end{tabular}

\section{Sample}

Through multi-stage random sampling data has been collected from the schools of Shamli, Muzaffarnagar, Saharanpur and Haridwar districts. A list of adolescent students were prepared and about $10 \%$ subjects were selected randomly through lottery from each institution. The final sample of 160 respondents was drawn from a large sample as per the requirement of cells of the research paradigm on the basis of high and low standard scores obtained on Emotional Maturity Scale and Comprehensive Marital Adjustment Inventory.

\section{Tools}

The following three psychological tests were used for collecting data from the universe.

1 Emotional Maturity Scale by Singh and Bhargava.

2 Comprehensive Marital Adjustment Inventory (unpublished) by Mishra.

3 Parent - Child Relationship Scale by Rao. 


\section{RESULTS}

The mean scores of each group was computed.

Table 2. Mean scores of the subjects on Parent-Child relationship scale.

\begin{tabular}{|c|c|c|c|c|}
\hline \multirow{2}{*}{$\begin{array}{c}\text { Parent's marital } \\
\text { adjustment }\end{array}$} & \multicolumn{4}{|c|}{ Parent's Emotional Maturity } \\
\cline { 2 - 5 } & Boys & Girls & Boys & Girls \\
\hline & 18.50 & 19.85 & 22.90 & 23.75 \\
\hline High & 29.00 & 22.65 & 28.20 & 24.95 \\
\hline Low & \multicolumn{4}{|c}{} \\
\hline
\end{tabular}

Table 3. Summary of ANOVA

\begin{tabular}{|l|l|l|l|l|}
\hline SOURCE OF VARIATIONS & S.S. & Df & M.S. & F \\
\hline Treatment & 1870.10 & 1 & 267.10 & \\
\hline Emotional Maturity of parents & 240.10 & 1 & 240.10 & $5.52^{*}$ \\
\hline Sex of adolescents & 136.90 & 1 & 136.90 & 3.14 \\
\hline Marital adjustment of parents & 980.10 & 1 & 980.10 & $22.54^{* *}$ \\
\hline Emo. M x Sex & 16.90 & 1 & 16.90 & 0.38 \\
\hline Emo. M x Mari. A & 115.60 & 1 & 115.60 & 2.65 \\
\hline Mari. A x Sex & 348.10 & 1 & 348.10 & $8.00 * *$ \\
\hline Emo. M x Sex x Mari. A & 32.40 & 1 & 32.40 & 0.74 \\
\hline $\begin{array}{l}\text { Error } \\
\text { Total }\end{array}$ & 6609.80 & 152 & 43.48 & \\
& 8479.90 & 159 & & \\
\hline
\end{tabular}

$\mathrm{P}^{*}<.05, \mathrm{P}^{* *}<.01$

Results of study were analyzed using the analysis of variance (ANOVA). Analysis revealed a significant effect of the independent variables that is emotional maturity and marital adjustment of parents while only one the interaction between marital adjustment of parents and sex of adolescents was found to be significant. The results in the table 3 show that adolescents of low emotional maturity of parents perceived their fathers as a rejecting figure to them. Further it depicts that adolescents of low maritally adjusted parents perceived their father rejecting to them. Further analysis reveals that boys perceive their fathers rejecting them than girls.

\section{DISCUSSION}

Adolescence is recognized as a period of crucial development due to many stresses and strains, which are experienced by the adolescents themselves as well as their parents (Bernhart, 1964; Patrick et.al, 1982). It is the time, during which boys and girls move from childhood to adulthood physically, emotionally, mentally and socially (Jersild, 1961) 


\section{Perception of Fathers Rejection in Adolescents}

The role of father usually relates to acting as a bridge by which the child reaches the outside world (Meerto, et.al, 1968, Bernhart and Alan, 1975) It symbolizes assertiveness and independence and provides both emotional and psychological support to the adolescents (Person, 1955; Johnson, R.C, 1969).

The Present study shows that adolescents of emotionally immature parents perceived their father rejecting them. Vig and Jaswal (2010) found emotionally well adjusted fathers were more accepting. Parents of high emotional maturity are better able to handle problems of their teens and hence have better relationships with their teenagers.

Present study reveals that adolescents of low maritally adjusted parents perceive their father rejecting them. Vig \& Jaswal (2010) were found positive influence of parental good marital relations on their adolescents and had more realistic role expectation from their sons \& daughters. Acceptance by fathers indicates positive attitude and their loving, affectionate and attentive behavior towards their children. Dasgupta and Basu (2002) reported that parentadolescents relationship and marital adjustment between spouses are closely interrelated. Kakkar, Alpna (1999) observed in tense stressful \& disturbing families adolescents perceive their parents rejecting \& neglecting. Khalique \& Rohner (2002) found in his study that perceived parental rejection is positively correlated with degree of maladjustment and parental acceptance is negatively correlated with maladjustment.

The current investigation expose that boys perceive their fathers more rejecting them then the girls, if their parents are maritally maladjusted. Kumar S. (2011) found that male adolescents perceived fathers to be significantly more neglecting, more rejecting as compared to the observation of female adolescents. Whereas the work of Munaf and Sardar (2010) indicates that the gender differences do exist for perception of childhood parental overprotection which was more for male then female child. Whereas no significant disparity in childhood parental rejection was noted. Stott, (1940b), Chen Soo; (1984) found that boys reported slightly more punishment, rejecting and more demanding by their fathers. Flouri and Buchanan (2003) found that the relationship between father's involvement and happiness was not stronger for boys than for girls. Thus we can say that emotional maturity and marital adjustment of parents and sex of adolescents affect the perception of fathers rejection in adolescents.

\section{CONCLUSION}

The present study measured perceived fathers rejection and its impact upon psychological adjustment of adolescents. It is obvious from the results that those adults who perceived their fathers as giving acceptance in adolescents were found to be more adjusted as compared to those adolescents who perceived their fathers as giving rejection in adolescents. This indicates the importance of stage of adolescents in later personality development and development of psychopathology. 


\section{Clinical Implications}

Clinical psychologists may focus upon negative adolescents experiences of their patients as a causative factor of their current maladaptive behavior. Hence by knowing the proper etiology it is possible to apply interventions and interpretation of their behavior more appropriately, which can be beneficial for smooth functioning of their clients. It can also be beneficial for parents as through parental counseling they can become aware of the negative consequences of their negative behavior towards their adolescents. This may help them to handle their adolescents in much healthier way.

\section{Acknowledgments}

The author appreciates all those who participated in the study and helped to facilitate the research process.

\section{Conflict of Interests}

The author declared no conflict of interests.

\section{REFERENCES}

Bernhart, L. (1964): Discipline and child guidance, New York, Mc Graw hill book company, 284-294.

Bernhart and Alan, J. (1975). The effect of labeled and unlabeled praise upon lower and middle class children. Journal of Experimental psychology, 19 (3), 536-543.

Boyes, M.C., and Allen S.G. (1993): Styles of parent-child interaction and moral reasoning in adolescence. Merill Palmer, Quar., 39,551-576.

Chen, Soo (1984): Parent-child relationship of Chinese gifted children, bulletin of educational psychology, 17, 131-149.

Dasgupta, S.\& Basu,J. (2002): Parent-adolescent relationship: The contributory role of marital quality of the parents and earning states of the mother. Indian Journal of psychological issues, 10, 40-51.

Dhar, Upender (1983): The psychological correlates of behavioral dynamics in the patients of hensen's diseases (unpub. Ph. D. Thesis), Agra university, Agra.

Flouri, E.\& Buchanan,A. (2003): The role of father involvement and mother involvement in adolescents psychological well being. British Journal of social work,33, 399-406.

Jersild, A.T. (1961): The psychology of adolescents. New York, the Mc Millan company, 116.

Johnson, M.M. (1969): Sex role learing in the nuclear family. Journal of child development., 34,257-258.

Kagan, J.(1978): The parental love trap. Psychology today, 54-91.

Kakkar, Alpana (1999): A study of parental acceptance rejection as related to the problem of adolescents. Indian Journal of Psychometry \& Education, 30(1), 23-30

Khalique, A.\& Rohner, R.P. (2002): Perceived parental acceptance-rejection and psychological adjustment. A meta analysis of cross cultural and intracultural studies, Journal of marriage and family, 64 (1),54-64.

Kumar, S. (2011), Parents Psycho-social maturity as correlates of adolescents adjustment $\left(1^{\text {st }}\right.$ Edition). Shivani Art Press, Sahadara, Dehli- 110032, 233-234 
Kuterovac, Jagodic, G. and Kerestes, G. (1997): Perception of parental acceptance-rejection and some personality variables in young adults. Journal of general social issues, 6, 4-5,477-491.

Marks, F.A. (2006): The effect of involved nonresidential fathers distress, parenting behaviors, interparental conflict and the quality of father-child relationship on children's well being. Fathering, men's studies press.

Meerto, J. A. (1968): The psychological role of the father. Journal of child and family, 7(2),102-116.

Mishra, O.P.: (1996): Comprehensive Marital Adjustment Inventory (Unpublished), Gurukul Kangri University, Haridwar.

Munaf, S. \& Sardar, H. (2010): Reminiscence of childhood parenting and psychological state of adults. Proceedings of 2010 international conference on humanities, Historical and Social sciences (CHHSS-2010), Feb. 26-28, Singapore.

Patrick, et. al. (1982): Adolescent discipline: different family member's perception. Journal of youth and adolescence, 10(5), 327-335.

Person, T. (1955): family structure and the socialization of the child. Family socialization and interactions process, Glen col., $3^{\text {rd }}$, free press.

Rao, Nalini (1971): Parent child Relationship Scale. National Psychological Corporation, Agra

Rohner, R.P. (1986): The warmth dimension: Foundations of parental acceptance- rejection theory. Beverly Hills. C. A. Sage Publications.

Rohner, R.P. (1998): Father love and development, current directions in psychological science, 7, 5, 157-161.

Rohner, R.P. (2004): The parental acceptance- rejection Syndrome : Universal correlates of perceived rejection. American Psychologist, 59, 830-840

Rohner, R.P, Khaleque, A. \& Cournoyer, D.E. (2005): Parental acceptance- rejection : Theory, Methods, cross cultural evidence and implications. Ethos, 33,299-334

Rohner, R.P.(1991): Handbook for the study of parental acceptance and rejection, storrs, CT: University of Connecticut.

Rohner, R.P., Bourque, S.L. \& Elordi, C.A. (1996): Children's perceptions of corporal punishment, caretaker acceptance and psychological adjustment in poor, biracial southern community. Journal of marriage and the family, 58, 842-852.

Singh, Y. \& Bhargava, M. (1984): Emotional maturity scale. National psychological Co. Agra.

Stott, L.H. (1940b): Home Punishment of adolescents. Journal of Genetic Psychology, 415-428

Symands, P.M. (1939): The psychology parents-child relationship, New York Appleton-century crofts.

Vig, D. and Jaswal, I.J.S. (2010): Emotional adjustment of parents and quality of parent-teen relationships, stud. Home science, 4 (1), 39-44.

How to cite this article: S Kumar (2016), Perception of Fathers Rejection in Adolescents, International Journal of Indian Psychology, Volume 3, Issue 4, No. 68, ISSN:2348-5396 (e), ISSN:2349-3429 (p), DIP:18.01.200/20160304, ISBN:978-1-365-39398-3 